\title{
SEMICONDUCTOR TO METAL TRANSITION IN $\mathrm{Hg}_{2} \mathrm{CLF}$
}

\author{
K. TENNAKONE* AND A. H. JAYATISSA \\ Department of Pbysics, University of Rubuna, Matara, Sri Lanka.
}

(Date of receipt : 01 July 1986)

(Date of acceptance : 10 February 1987)

Experimental and theoretical investigations on conductivity transitions in solid materials have attracted much attention. It is well known that some inorganic compounds undergo transition from semiconductor or insulator phase to metallic state upon heating/1-4/. In this note we report our observations on semiconductor to metal transition in mercurous chlorofluoride. This material undergo transition into a metallic state at $369 \mathrm{~K}$ and the conductivity in metallic state is unusually high $\simeq 177 \Omega^{-1} \mathrm{~m}^{-1}$.

$\mathrm{Hg}_{2} \mathrm{ClF}$ is prepared by the following method. An aqueous solution of mercurous nitrate $(0.1 \mathrm{M})$ is added dropwise to mixture containing dil $\mathrm{HCl}$ and $\mathrm{NaF}(0.5 \mathrm{M}$ in $\mathrm{HCl}$ and $0.5 \mathrm{M}$ in $\mathrm{NaF}) . \mathrm{Hg}_{2} \mathrm{ClF}$ that separates out as a chocolate brown-precipitate is washed and dried at $423 \mathrm{~K}$. Chemical analysis indicate that the compound has stoicheiometric composition corresponding to $\mathrm{Hg}_{2} \mathrm{ClF}$ (molar ratio $\mathrm{Hg}: \mathrm{Cl}: \mathrm{F} \in 2: 1.05: 0.92$ ).

To measure the conductivity, the powder is compacted into a glass tube (diameter $\sim 0.8 \mathrm{~cm}$ ) and pressed between stainless steel electrodes to a pressure of $2 \times 10^{6} \mathrm{pa}$, when a pellet (length $\sim 0.6 \mathrm{~cm}$ ) is formed. The ends of the tube are sealed with epoxy resin, the sample is immersed in a thermostatic oil bath and the d.c. resistance at different temperatures is measured using a resistance meter (Computing Digital Multimeter, Takeda Riken Model 6877$)$. The room temperature $\left(30^{\circ} \mathrm{C}\right)$ conductivity of the material is $177 \Omega^{-1} \mathrm{~m}^{-1}$ (quite high for an inorganic compound). The plot of $\ln \delta$ vs $\mathrm{T}^{-1}$ is indicated in Figure 1. The transition to metallic state occurs at $369 \mathrm{~K}$ and the conductivity thereafter gradually decreases with the increase of temperature, the maximum conductivity is $\sim 215 \Omega^{-1} \mathrm{~m}^{-1}$. Current-voltage characteristics are found to be linear at all temperatures. Again polarization effects are not detected and results are independent of the electrode material and a.c. measurements show the same, behaviour. Above observations indicate that the conductivity is electronic and ionic conduction is negligible or absent.

Attempts were made to prepare single crystals of $\mathrm{Hg}_{2} \mathrm{ClF}$ by diffusion and gel methods, sizeable crystals could not be obtained. Again authors had no facilities to elucidate the crystal structure of $\mathrm{Hg}_{2} \mathrm{ClF}$.

* Institute of Fundamental Studies, Sri Lanka. 


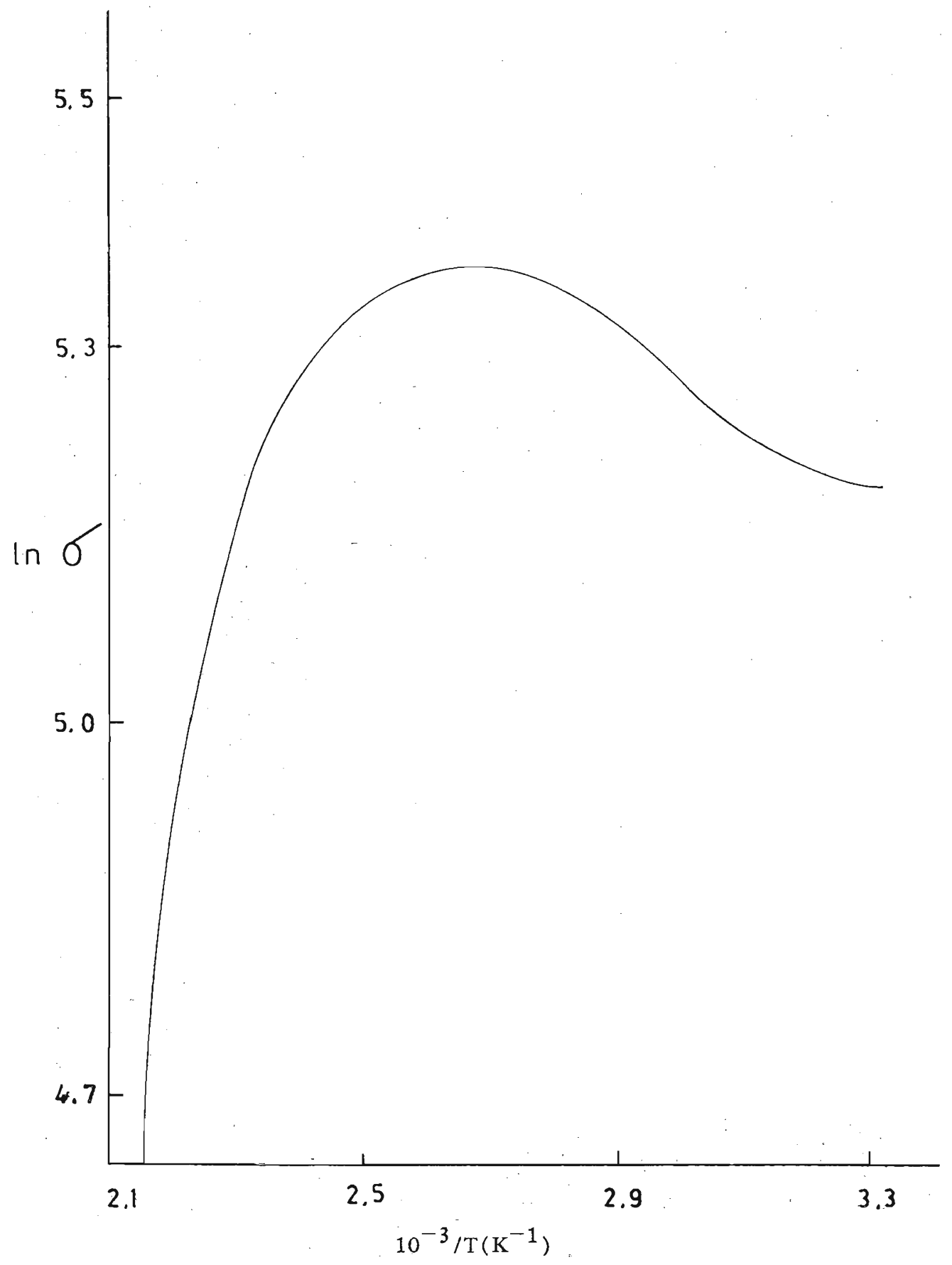

Figure 1: Plot of $\ln \sigma\left(\sigma\right.$ in $\left.\Omega^{-1} \mathrm{~m}^{-1}\right)$ vs $\mathrm{T}^{-1}$ 


\section{References}

1. AUSTIN, I. G. \& MOTT, N. F. (1970). Science, $168: 71$.

2. $\quad$ MOTT, N. F. (1956). Can. J. Phys. $34: 1356$.

3. MOTT. N. F. \& DAVIS, E. A. (1971) Electronic Processes in NonCrystalline Solids, Oxford University Press, London.

4. SWENUMSON, R. D. \& EVEN, U. (1981). Phys. Rev. B., $24: 5743$. 